\title{
Hyaluronidase Proof for Endothelial Glycocalyx as Partaker of Microcirculation Disturbances
}

\author{
Alexander Maksimenko ${ }^{1}$, Askar Turashev ${ }^{1}$, Andrey Fedorovich ${ }^{2}$, Anatoly Rogoza ${ }^{2}$ and Elena Tischenko ${ }^{1}$ \\ 1. Institute of Experimental Cardiology, Russian Cardiology Research and Production Complex, Moscow 121552, Russia \\ 2. A.L. Myasnikov Institute of Clinical Cardiology, Russian Cardiology Research and Production Complex, Moscow 121552, Russia
}

Received: September 06, 2012 / Accepted: December 03, 2012 / Published: February 28, 2013.

\begin{abstract}
Covalent modification of bovine testicular hyaluronidase with chondroitin sulphate led to changes in the pattern of glycation of native and modified enzyme in its reaction with neutral saccharides and N-acetylhexosamines. Thus, mono- and di-saccharides inactivated the native hyaluronidase to a greater extent than the chondroitin sulfate-modified enzyme. $\mathrm{N}$-acetylhexosamine, on the opposite, inactivated the modified hyaluronidase to a greater extent than the native one. These properties made it possible to use native and modified hyaluronidase as an informative research system for in vivo measurement of the predominant type of saccharide agents in the circulation. The proposed approach was experimentally substantiated by obtained results of the study on these interactions of hyaluronidase derivatives with hyaluronan fragments and their mixture. In a model of post-ischemic perfusion of the rat limb, the effect of hyaluronidase derivatives and their components on restoration of the microcirculation were tracked using laser Doppler flowmetry. Native hyaluronidase accelerated the restoration of initial level of microcirculation, but modified enzyme was markedly inhibited by glycocalyx degradation products. N-acetylhexosamine was positioned at the reducing terminal of these products as a natural label for these glycocalyx fragments. These and other data obtained under various experimental conditions supported the participation of endothelial glycocalyx in microcirculation disturbances.
\end{abstract}

Key words: Microcirculation, vascular biology, endothelial glycocalyx, chondroitin sulfate, hyaluronidase, laser Doppler flowmetry.

$\begin{array}{ll}\text { Abbreviations } \\ \text { HU } & \text { native hyaluronidase } \\ \text { CHS } & \text { chondroitin sulphate } \\ \text { HU-CHS } & \text { chondroitin sulphate-modified hyaluronidase } \\ \text { HU+CHS } & \text { mixture of chondroitin sulphate with hyaluronidase } \\ \text { GAG } & \text { glycosaminoglycans } \\ \text { BSA } & \text { bovine serum albumin } \\ \text { LDF } & \text { laser Doppler flowmetry } \\ \text { GLX } & \text { endothelial glycocalyx } \\ \text { MCB } & \text { microcirculatory bed }\end{array}$

\section{Introduction}

Vascular biology has been elicited the culprits and custodians of vessel wall function so far. Vascular wall injury is really involved in the pathogenesis of most cardiovascular diseases. In a normal blood vessel,

Corresponding author: Alexander Maksimenko, Ph.D., professor, research fields: vascular biology and biochemistry. E-mail: alexmak@cardio.ru. the wall is protected by a double protective layer: the endothelium and its glycocalyx $[1,2]$. The glycocalyx has several functions: an inert barrier, a molecular sieve, a reservoir for biologically active compounds, and a mechanical transducer of shear stress from blood flow on the endothelium [3, 4]. Endothelial GLX (glycocalyx) is composed mainly of membrane (syndecans, glypicans) and soluble (perlecan, biglycan, etc.) proteoglycans. These proteoglycans, in turn, vary according to the different glycosaminoglycans (heparin sulfate, chondroitin sulphate, keratan sulphate, dermatan sulphate) bound to the proteoglycan skeleton $[5,6]$. There is the hyaluronic acid also as exclusive case of nonsulphated glycosaminoglycan with unknown exact link to the cell membrane. 
The composition of GLX is not constant, rather, it exists in dynamic equilibrium with the blood flowing past by exchanging soluble components. This process underlies the formation of the endothelial surface layer [7]. Taken together the components of GLX form a self-renewing three-dimensional network composed of various polysaccharides and protein derivatives [5-8]. As proposed, disruption of GLX caused by reactive oxygen species $[3,9]$, ischemia [7, $9,10]$, reperfusion $[11,12]$, or enzymatic action $[3,5$, $7,9]$ represents an early stage of subsequent vascular injury [3-9]. Due to their ability to cleave GLX components, the glycosidases or proteases can change the density of the protective cover layer, which, in turn, affects blood flow. Acute changes in blood flow can have severe and even lethal consequences for the outcome of cardiovascular disease [13]. Yet, recovery of heart function after acute myocardial infarction is possible in some cases (25\%) after achieving significant perfusion in the infarct-related artery and restoration of adequate microcirculation level and tissues perfusion [14-16]. Thus, significant improvement in macro- and micro-circulation is crucial for successful therapy $[15,17,18]$. Biochemical determination of glycocalyx share in vascular injury implies therapeutically the possibility to regulate glycocalyx state with help of biochemical methods and means.

According to the commonly accepted concept, all blood vessels have GLX, larger vessels have thicker GLX layers [5]. GLX in large vessels can be visualized using two-photon laser scanning microscopy [19, 20]. It is justifiably assumed that GLX dysfunction can trigger the development of atherothrombosis [21]. GLX in large blood vessels has been shown to be similar to that in capillaries [22]. However, there are very few data on the role of GLX in the microcirculation and its disorders [3]. Most reports interpret microcirculatory defects as a result of vasoconstriction and/or microembolization [23] caused by fragments of a lysed thrombus, ruptures of an atherosclerotic plaque, large platelets, or platelets aggregated with red and white blood cells $[3,17]$. The authors believe that the role of GLX in the development of microcirculatory disorders has been underestimated. GLX must be intimately involved in this pathological process, since a diminishing luminal diameter brings the opposing sides of the vascular wall very close to each other and to the clogging material.

In the present study, the authors aimed at elucidating the role of GLX in microcirculatory disorders. For this purpose, the model of ischemic injury was used to MCB (the microcirculatory bed) in the rat hind limb. Subcutaneous microcirculation was monitored by LDF (laser Doppler Flowmetry). The presence of GLX components in the circulation was identified using hyaluronidase derivatives, BSA and CHS.

\section{Materials and Methods}

\subsection{Materials}

Bovine testicular hyaluronidase (under commercial name Lidase ${ }^{\circledR}$, EC 3.2.1.35) from "Microgen" (Moscow, Russia) was further purified using gel-chromatography (Sephadex G-100, Pharmacia, Sweden). The specific activity of the final enzyme preparation was 950-970 NFU/mg protein. Chondroitin sulphate-modified hyaluronidase (HU-CHS) was prepared as described earlier [24]. The specific activity of HU-CHS was 720-750 NFU/mg protein; $84-86 \%$ of the surface amino groups were modified and the preparation contained $3-6 \%$ protein $[24,25]$.

Other reagents: Hyaluronic acid potassium salt (hyaluronan) with a mean molecular mass (MM) of 700-800 kDa prepared from human umbilical cord, CHS (chondroitin-4-sulphate) from bovine trachea (MM 30-50 kDa), BSA (bovine serum albumin), D-glucose, D-galactose, D-maltose, D-lactose, D-cellobiose, N-acetylglucosamine and Nacetylgalactosamine, sodium chloride-all from 
Sigma, USA.

Individual fragments (oligomers) of hyaluronic acid with the brutto-formula GlcA-[--GlcNHAcGlcA-- $]_{n}---G l c N H A c$, where $n$ is 0 (dimer), 1 (tetramer), 2 (hexamer), 3 (octamer), 4 (decamer) of hyaluronan were kindly gifted by Prof. Keiichi Takagaki, Department of Biochemistry, Hirosaki University School of Medicine, Hirosaki, Japan [26]. All other reagents and chemicals were manufactured in the Russian Federation and were of analytical grade.

\subsection{Methods}

The endoglycosidase activity of $\mathrm{HU}$ (hyaluronidase) derivatives was determined using an Ostwald viscometer (B-434, Cannon, USA) as described in Ref. [27]. The time required for the test solution to flow through the apparatus was measured at $37{ }^{\circ} \mathrm{C}$. The reagent mixture contained phosphate buffer $(0.1 \mathrm{M}$, pH 5.5), $\mathrm{NaCl}(0.15 \mathrm{M}), \mathrm{HU}(0.002 \mathrm{mg} / \mathrm{mL})$, monoor disaccharides, or $\mathrm{N}$-acetylhexosamines $(0.2$ $\mathrm{mg} / \mathrm{mL})$, heparin $(0.2 \mathrm{mg} / \mathrm{mL})$. Prior to the measurement, $0.1 \mathrm{~mL}$ of this mixture was added to 0.9 $\mathrm{mL}$ of hyaluronic acid (the substrate) to bring its final concentration to $0.06 \%$, and the sample was transferred to the viscometer.

The ratio of the flow time of this reaction mixture to the flow time of the enzyme-free solution was taken as the relative viscosity of the tested sample. The enzymatic reaction velocity was calculated from the slope of the reverse logarithm of the relative velocity plotted against the time of incubation/measurement [25]. The calculated values reflected the relative velocity of enzymatic conversion of the substrate, these were compared with the similar values for $\mathrm{HU}$ standards (bovine testicular HU, Sigma, USA). The relative specific activity of the standard (further purified) $\mathrm{HU}$ product was $950-970 \mathrm{NFU} / \mathrm{mg}$ protein, this value was taken as $100 \%$. Each sample containing the tested HU derivatives was measured three times, the mean value of these measurements is reported.
The error of method was $\pm 2-3 \%$.

HU-CHS was prepared by the previously developed original procedure [24]. The protein content of both native and modified preparations was determined according to Bradford [28]. The surface amino groups of $\mathrm{HU}$ were titrated with picrysulfnic acid [25, 29].

The effect of the ionic strength on HU activity was determined under increasing concentrations of $\mathrm{NaCl}$ $(0.05,0.1,0.15,0.25,0.5,0.75$, and $1.0 \mathrm{M})$ at $37^{\circ} \mathrm{C}$. The reagent solution was buffered at $\mathrm{pH} 5.5$ and $\mathrm{pH}$ 7.5 for native and modified enzyme. The measurements were done in triplicate.

To modify HU, the native enzyme was incubated with at least 100-fold molar excess of saccharides (mono- or disaccharides, N-acetylhexosamines, or hyaluronan fragments with the $n$ from 0 to 4 ). The incubation was carried out in $0.05 \mathrm{M}$ phosphate buffer (pH 5.5 or 7.5) in the presence of $0.15 \mathrm{M}$ or $0.75 \mathrm{M}$ $\mathrm{NaCl}$ at $37{ }^{\circ} \mathrm{C}$. Protein was present at $0.02 \mathrm{mg} / \mathrm{mL}$, $\mathrm{N}$-acetylhexosamine or other saccharide at $2 \mathrm{mg} / \mathrm{mL}$, and hyaluronan fragments at $0.01 \mathrm{mg} / \mathrm{mL}$ or higher. The addition of sodium azide at $0.05 \%$ had no effect on the results. During the incubation for either four hours or eight days, aliquots of $0.1 \mathrm{~mL}$ were withdrawn from the reaction mixture and were tested for their endoglycosidase activity. The addition of hyaluronan fragments to the buffered substrate solution did not change the flow time or the respective viscosity (within the measurement error of $\pm 3 \%$ ), it decreased by no more than $3-4 \%$ of the initial value for the entire incubation period of four hours at $\mathrm{pH} 5.5$ and $37^{\circ} \mathrm{C}$.

Resistance of the HU derivative to inhibition by heparin was assessed by the residual enzymatic activity measured in the presence of excess heparin (weight ratio HU:heparin $=1: 100)[24,25]$. To the reaction mixture containing a standard amount of protein $(2 \mu \mathrm{g} / \mathrm{mL})$ in $0.1 \mathrm{M}$ phosphate buffer ( $\mathrm{pH} 5.5$ ) was added $0.2 \mathrm{mg} / \mathrm{mL}$ heparin. With $2-4 \mathrm{~min}$ incubation at room temperature, the endoglycosidase 
activity of $\mathrm{HU}$ derivatives was quantified using an Ostwald viscometer. Heparin by itself did not change the flow time of the buffer solution. The results represent the means of three measurements.

\subsection{In Vivo Experiments}

Male Wistar rats $(320-400 \mathrm{~g})$ were anesthetized with chloroform. To simulate ischemia, a hind limb was clamped at the knee area using a hollow plastic tube and a lavsan thread passed through the tube. The pressure on the limb was controlled by tightening or loosening the thread using a surgical mosquito clamp. Tissue perfusion was measured by LDF (Laser Doppler flowmetry). The single-channel LDF analyzer LAKK-02 (Lasma, Russia) operating in the visible red range $(\lambda=630 \mathrm{~nm})$ allowed the measurement of microcirculation blood flow at a depth of $1 \mathrm{~mm}$ (1.0-1.5 $\mathrm{mm}^{3}$ of tissue mass). This methodology is advantageous as compared to others because it permits analysis not only of the volume/velocity parameters of blood micro-flow, but of the individual mechanisms that control this flow as well.

The red laser detector was attached (strictly perpendicularly) to the surface of the crease of the interdigital pads of the rat left hind limb. Two infusion regimens were used to study the effects of the tested agents on microcirculation and its recovery after ischemia. Scheme 1: bolus injection $(1 \mathrm{~mL}$ solution into the tail vein) $1 \mathrm{~min}$ prior to $3 \mathrm{~h}$ ischemia (systemic effect); and Scheme 2: bolus injection $5 \mathrm{~min}$ before the end of $3 \mathrm{~h}$ ischemia (acute effect). The same volume of saline was injected in the control group. The microcirculation level was measured before, after, and during the ischemic period. The experimental animals showing similar levels of post-ischemic microcirculation recovery (within $5 \mathrm{~min}$ ) were grouped together (Table 1).

\subsection{Wavelet Analysis of the Experimental Data}

For the calculations, the microcirculation levels were noted every $60 \mathrm{~s}$ for the $5 \mathrm{~min}$ pre-ischemic period and every $30 \mathrm{~s}$ for the post-ischemic recovery (10 $\mathrm{min}$ or $20 \mathrm{~min}$ ). These numbers were then expressed as the ratios of the microcirculation level at the given moment to the average level in the initial period. The selected 5 min interval is the minimum period required for collecting enough data for subsequent amplitude-frequency analysis and wavelet transformation [30].

Each frequency range of the obtained spectrum was analyzed separately, which made it possible to distinguish between various modifiers of blood flow: heart or respiratory rhythm, myogenic, neurogenic, or endothelial factors. In the amplitude-frequency analysis of the reflected signal after wavelet transformation, the above five effectors can be identified according to five specific frequency ranges.

The software used (LDF 2.2.0.507) was not applicable for frequencies above $1.5 \mathrm{~Hz}$. Therefore, the authors were not able to measure the effects of heart

Table 1 Names and doses of the tested derivatives, numbers of animals in the experimental groups.

\begin{tabular}{|c|c|c|c|c|}
\hline \multirow{2}{*}{ Injected Preparation } & \multicolumn{2}{|c|}{ Scheme 1} & \multicolumn{2}{|c|}{ Scheme 2} \\
\hline & Dose & Number of animals & Dose & Number of animals \\
\hline Control (saline) & $1 \mathrm{~mL}$ & 6 & $1 \mathrm{~mL}$ & 6 \\
\hline $\mathrm{HU}$ & $\begin{array}{l}3 \mathrm{mg} \text { protein } / \mathrm{kg} \\
(2,800-2,900 \mathrm{NFU} / \mathrm{kg})\end{array}$ & 6 & $\begin{array}{l}3 \mathrm{mg} \text { protein/kg } \\
(2,800-2,900 \mathrm{NFU} / \mathrm{kg})\end{array}$ & 6 \\
\hline HU-CHS & $\begin{array}{l}3 \mathrm{mg} \text { protein/kg } \\
(2,200-2,300 \mathrm{NFU} / \mathrm{kg})\end{array}$ & 6 & $\begin{array}{l}3 \mathrm{mg} \text { protein/kg } \\
(2,200-2,300 \mathrm{NFU} / \mathrm{kg})\end{array}$ & 6 \\
\hline Free CHS & $5 \mathrm{mg} / \mathrm{kg}$ & 6 & $5 \mathrm{mg} / \mathrm{kg}$ & 6 \\
\hline $\mathrm{HU}+\mathrm{CHS}$ & $\begin{array}{l}5 \mathrm{mg} \text { glycosaminoglycan } / \mathrm{kg} \\
\text { and } 3 \mathrm{mg} \text { protein } / \mathrm{kg} \\
(2,800-2,900 \mathrm{NFU} / \mathrm{kg})\end{array}$ & 6 & $\begin{array}{l}5 \mathrm{mg} \text { glycosaminoglycan } / \mathrm{kg} \\
\text { and } 3 \mathrm{mg} \text { protein } / \mathrm{kg} \\
(2,800-2,900 \mathrm{NFU} / \mathrm{kg})\end{array}$ & 6 \\
\hline BSA & $3 \mathrm{mg}$ protein $/ \mathrm{kg}$ & 4 & $3 \mathrm{mg}$ protein $/ \mathrm{kg}$ & 4 \\
\hline
\end{tabular}


rhythm (4-5 Hz in the rat) on microcirculation. Instead, it was possible to concentrate on those "active" factors that influence microcirculation by altering vascular tone: the endothelial $(0.01-0.08 \mathrm{~Hz}$ in the rat), neurogenic $(0.08-0.2 \mathrm{~Hz})$, and myogenic $(0.2-0.7 \mathrm{~Hz})$ rhythms $[30,31]$.

\subsection{Statistical Analysis}

The significance of the differences between various groups of data was evaluated using the Kruskal-Wallis non-parametric ANOVA method. The comparison between various frequency ranges within the same time interval for different study groups $(\mathrm{P} \leq 0.05)$ and between various time intervals within the same group was made by the median test. The significance of the differences between various time intervals within the same group was tested by the non-parametric sign criteria and the Wilcoxon criteria (for Scheme 1), as well as by rank analysis of variance (Friedman ANOVA, $P \leq 0.05$ ) and computation of Kendall's coefficient of concordance (for Scheme 2). Since the effects observed in the Scheme 2 experiments developed more slowly than in Scheme 1, the authors selected four time intervals for Scheme 2 and only two time intervals for Scheme 1. The Kruskal-Wallis non-parametric ANOVA method $(\mathrm{P}<0.05)$ and the median test were also used for the comparison between the times needed to reach the initial level of microcirculation in both experimental schemes. To rule out the problem of multiple comparisons and validate the use of the Kruskal-Wallis test, the authors compared paired groups by the non-parametric Mann-Whitney test and the Bonferroni correction for the p-value.

The statistical data presented in the Tables include the number of animals, the medians, the $95 \% \mathrm{CI}$ (confidence intervals), the interquartile ranges (or interquartile values), the name of the test used, and the precise value of the p-parameter. For groups with where $n$ is equal 6 , the $95 \%$ CIs show the minimal and maximal values of the given parameter in this group.

\section{Results and Discussion}

\subsection{Biochemical Test of Glycocalyx}

One of major components of GLX - hyaluronan is essential for normal functioning of blood capillaries. It plays a regulatory role in the permeability of the capillary wall and intercellular endothelial contacts $[3,32]$. HU which specifically destroys hyaluronan caused severe damage to MCB of subcutaneous tissue in hamsters [33]. Based on these reports, the authors chose HU to regulate the state of the GLX of the microcirculation. In vivo, the enzymatic activity of HU depends on its saccharide environment, which also determines HU resistance to heparin inhibition [24]. Authors sought to simulate changes in this environment. By covalently modifying the $\mathrm{HU}$ structure with different GAG (glycosaminoglycans), the authors showed that polymeric GAG (hyaluronan, CHS) stabilized the enzyme, whereas co-polymeric GAG (heparin, dermatan sulfate) destabilized it. The inactivation of $\mathrm{HU}$ was due to the presence of iduronic acid as well as $\alpha(1-3)$ and $\alpha(1-4)$ glycoside bonds in the enzyme microenvironment. In contrast, the presence of CHS caused the greatest stabilizing effect on HU and its endoglycosidase activity [24]. In vivo, $\mathrm{HU}$ interacts with low-molecular-weight saccharides (resulting from carbohydrate exchange disturbances) as well as with GLX degradation products (resulting from ischemia/reperfusion or oxidative stress). In the first scenario, HU binds neutral mono- or disaccharides; in the second Scenario, ionized products of GLX degradation; in both cases, HU enzymatic activity can vary. It should be noted that glycation alters the protein properties straightway with interaction start and can continue long time [34, 35].

The authors compared the glycation patterns of $\mathrm{HU}$ and HU-CHS after their reactions with either mono(glucose, galactose) or di- (maltose, cellobiose, lactose) saccharides. As shown in Tables 2 and 3, native HU was less active and less resistant to heparin inhibition 
as compared with HU-CHS. It is probable that CHS formed a protective shield around the enzyme molecule, and thus prevented its glycation by neutral mono- or di-saccharides and preserved its enzymatic activity. Binding with CHS caused a different type of conformational changes similar to those caused in HU with glycation by a mixture of various saccharides. As proposed, those changes help maintain the proper saccharide environment around the HU globular molecule [9].
In the next step, the authors studied the interaction of HU with N-acetylhexosamines. Nacetylglucosamine and $\mathrm{N}$-acetylgalactosamine were selected because these two saccharides are located at the reducing terminal of GAG produced by degradation of GLX. As shown in Tables 2 and 3, the HU-CHS treated with $\mathrm{N}$-acetylhexosamines was less active and less resistant to heparin inhibition as compared with the native enzyme. The authors then concluded that the effects of $\mathrm{N}$-acetylhexosamines on

Table 2 Glycation of HU by mono- (glucose and galactose), di- (maltose, cellobiose, lactose) saccharides, and $\mathrm{N}$-acetylhexosamines ( $\mathrm{N}$-acetylglucosamine and $\mathrm{N}$-acetylgalactosamine) after incubation in $\mathrm{NaCl} 0.15 \mathrm{M}$ for 8 days at $37^{\circ} \mathrm{C}$.

\begin{tabular}{|c|c|c|c|c|}
\hline \multirow[t]{3}{*}{ Incubation mixture } & \multicolumn{4}{|c|}{ HU characteristics with 8 days incubation } \\
\hline & \multicolumn{2}{|c|}{ pH 5.5} & \multicolumn{2}{|r|}{$\mathrm{pH} 7.5$} \\
\hline & $\begin{array}{l}\text { Residual activity } \\
\text { (\% from initial) }\end{array}$ & $\begin{array}{l}\text { Residual activity in } \\
\text { the presence of excess } \\
\text { heparin }(\% \text { of initial })\end{array}$ & $\begin{array}{l}\text { Residual activity } \\
\text { (\% from initial) }\end{array}$ & $\begin{array}{l}\text { Residual activity in the } \\
\text { presence of excess } \\
\text { heparin ( } \% \text { of initial) }\end{array}$ \\
\hline $\mathrm{HU}$ & 80 & 72 & 82 & 68 \\
\hline HU plus glucose & 85 & 33 & 70 & 44 \\
\hline HU plus galactose & 65 & 55 & 80 & 60 \\
\hline HU plus glucose and galactose & 61 & 54 & 66 & 60 \\
\hline HU plus maltose & 88 & 23 & 96 & 28 \\
\hline HU plus cellobiose & 99 & 14 & 95 & 12 \\
\hline HU plus lactose & 58 & 14 & 71 & 15 \\
\hline HU plus maltose, cellobiose and lactose & 57 & 2 & 56 & 1 \\
\hline HU plus $\mathrm{N}$-acetylglucosamine & 78 & 68 & 80 & 70 \\
\hline HU plus $\mathrm{N}$-acetylgalactosamine & 88 & 78 & 86 & 77 \\
\hline $\begin{array}{l}\text { HU plus } \mathrm{N} \text {-acetylglucosamine and } \\
\text { N-acetylgalactosamine }\end{array}$ & 70 & 60 & 80 & 70 \\
\hline
\end{tabular}

Table 3 Glycation of HU-CHS by mono- (glucose and galactose), di- (maltose, cellobiose, lactose) saccharides, and $\mathrm{N}$-acetylhexosamines ( $\mathrm{N}$-acetylglucosamine and $\mathrm{N}$-acetylgalactosamine) after incubation in $\mathrm{NaCl} 0.15 \mathrm{M}$ for 8 days at $37^{\circ} \mathrm{C}$.

\begin{tabular}{|c|c|c|c|c|}
\hline \multirow[t]{3}{*}{ Incubation mixture } & \multicolumn{4}{|c|}{ HU-CHS characteristics with 8 days incubation } \\
\hline & \multicolumn{2}{|r|}{ pH 5.5} & \multicolumn{2}{|c|}{$\mathrm{pH} 7.5$} \\
\hline & $\begin{array}{l}\text { Residual activity } \\
\text { (\% from initial) }\end{array}$ & $\begin{array}{l}\text { Residual activity in the } \\
\text { presence of ( } \% \text { of initial) }\end{array}$ & $\begin{array}{l}\text { Residual activity } \\
(\% \text { from initial) }\end{array}$ & $\begin{array}{l}\text { Residual activity in the } \\
\text { presence of ( } \% \text { of initial) }\end{array}$ \\
\hline HU-CHS & 92 & 90 & 98 & 98 \\
\hline HU-CHS plus glucose & 96 & 93 & 87 & 97 \\
\hline HU-CHS plus galactose & 100 & 95 & 98 & 96 \\
\hline HU-CHS plus glucose and galactose & 85 & 88 & 82 & 83 \\
\hline HU-CHS plus maltose & 96 & 81 & 100 & 87 \\
\hline HU-CHS plus cellobiose & 88 & 71 & 91 & 75 \\
\hline HU-CHS plus lactose & 101 & 78 & 102 & 79 \\
\hline $\begin{array}{l}\text { HU-CHS plus maltose, cellobiose and } \\
\text { lactose }\end{array}$ & 75 & 66 & 72 & 72 \\
\hline HU-CHS plus N-acetylglucosamine & 44 & 33 & 12 & 4 \\
\hline HU-CHS plus $\mathrm{N}$-acetylgalactosamine & 50 & 37 & 38 & 25 \\
\hline $\begin{array}{l}\text { HU-CHS plus N-acetylglucosamine } \\
\text { and N-acetylgalactosamine }\end{array}$ & 42 & 31 & 18 & 6 \\
\hline
\end{tabular}


HU were opposite to those caused by mono- and disaccharides.

To explain these differences, the authors hypothesized that the negatively charged CHS altered the electrostatic interactions in the HU molecule. If this were the case, it could be detected by changes in pI with HU modification (computational pI for the native form is 8.62 [36]). To test this assumption, the authors measured the enzymatic activities of both HU forms under increasing ionic strength. However, there were no differences between the native and modified forms of $\mathrm{HU}$ (Fig. 1).

In an alternative approach, the authors tested whether the electrostatic interactions could play a
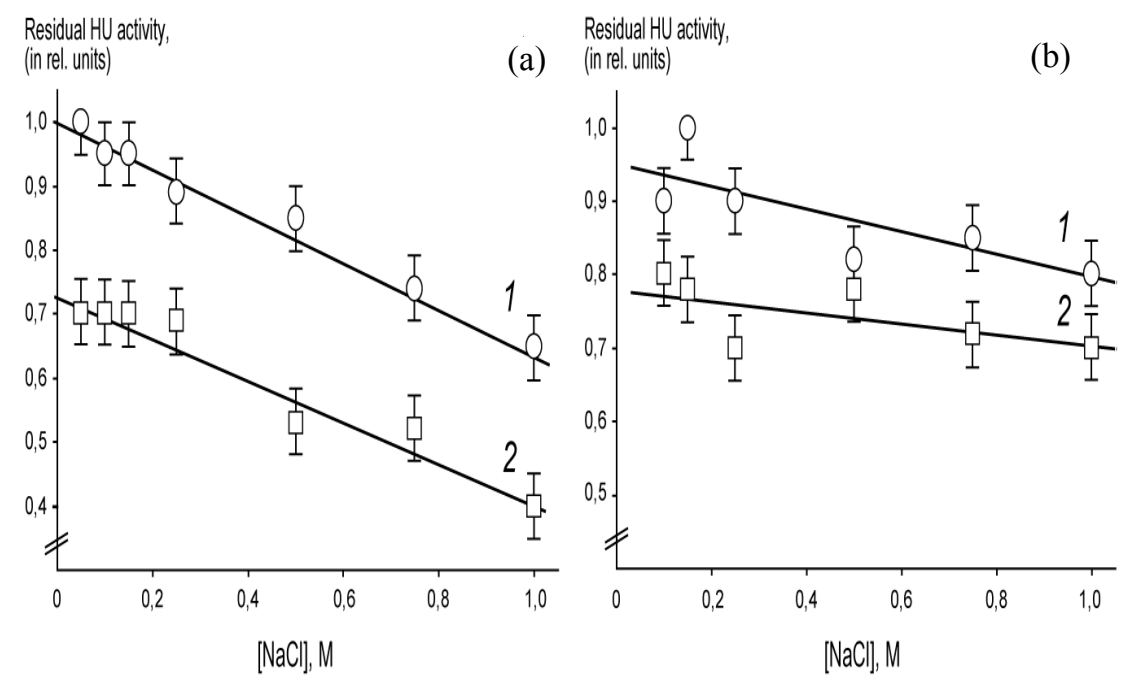

role in the reactions of $\mathrm{HU}$ with the modifying saccharides rather than in the act of catalysis. It was found that ionic strength had no effect on the glycation pattern of native $\mathrm{HU}$, and had a perceptible effect on the modified enzyme only after long incubations (Fig. 2).

In addition, the effects of ionic strength were more pronounced at $\mathrm{pH} 7.5$ than at $\mathrm{pH} 5.5$, and the inactivation curves for both HU forms were similar at short incubation periods (Fig. 2). Taken together these observations indicated that the electrostatic interactions could not be the critical factor that determined the behavior of native versus modified HU.

Other mechanisms can include (1) different protein

Fig. 1 The effect of ionic strength ( $\mathrm{NaCl}, \mathrm{M})$ on endoglycosidase activity of $\mathrm{HU}(1), \mathrm{HU}-\mathrm{CHS}(2)$ at (a) $\mathrm{pH} 5.5$ and (b) pH 7.5.
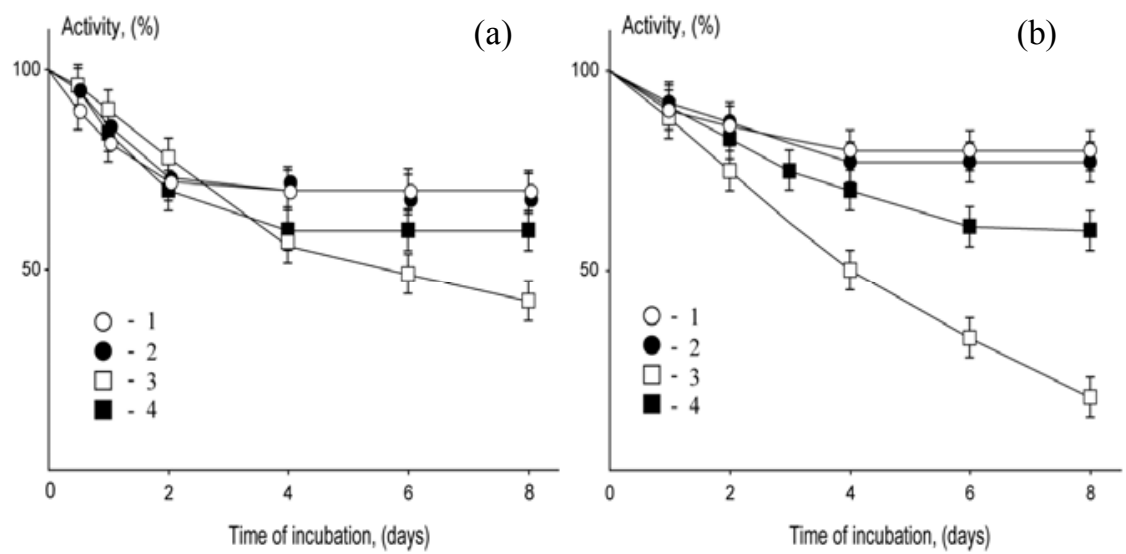

Fig. 2 Relationship of residual endoglycosidase activity of $\mathrm{HU}$ derivatives in their reaction with the mixture of $\mathrm{N}$-acetylglucosamine and $\mathrm{N}$-acetylgalactosamine at $\mathrm{pH} 5.5$ (a) and $\mathrm{pH} 7.5$ (b). The reagents were incubated in $\mathrm{NaCl}$ at $0.15 \mathrm{M}$ (HU: 1, HU-CHS: 3) or 0.75 M (HU: 2, HU-CHS: 4). 
conformations (curve 4 did not fully match curves 1 and 2 in Fig. 2), (2) different sensitivity to $\mathrm{pH}$ (different shapes and positions of the curves in Fig. $2 \mathrm{a}$ and $2 \mathrm{~b}$ ), (3) the multi-step process for formation of various HU glycation products (Fig. 3a), especially after prolonged incubation [9, 24, 25]. In addition, the bovine testicular HU preparation used might contain some contaminating enzyme$\mathrm{N}$-deacetylase that could convert the near-reducing terminus N-acetylglucosamine (Fig. 3b) into glucosamine [37]. These saccharides were reported to inhibit alkaline phosphatase [38]. As to $\mathrm{N}$-acetylhexosamines, they glycate the amide group of asparagine in ovalbumin [39] and in the surface S-layer of Halobacter halobium [40], and interact with other proteins [41].

In the circulation, $\mathrm{N}$-acetylhexosamines can be found only as part of GLX or its degradation products. In vivo, $\mathrm{N}$-acetylhexosamines as probed with native or modified HU can be used as biogenic markers for GLX degradation induced by vascular damage (Fig. 3b).

Notably, the carbonyl of the reducing terminal of hyaluronan oligosaccharides (from 4 to 40 saccharide residues in length) was found to bind a fluorescent label (2-aminobenzoic acid) [42]. In another study,hyaluronan oligosaccharides with a molecular weight less than $2.5 \mathrm{kDa}$ inhibited the enzyme phosphoinositide-3-kinase, whereas similar products of a higher molecular weight ( 80 or $2000 \mathrm{kDa}$ ) had no effect [43]. The quoted reports corroborate the results on the different responses of different HU derivatives to mono- and disaccharides in vitro. These saccharides accumulate in the blood due to carbohydrate imbalance; accordingly, the HU derivatives can be used to detect this metabolic pathology in vivo. Similar reasoning is applicable to circulating N-hexosamines that build up with GLX degradation.

In the present study, hyaluronan fragments with the brutto formula GlcA-[--GlcNHAc- GlcA-- $]_{\mathrm{n}}$ ---GlcNHAc (where $n$ varies from 0 to 4 ) inactivated
HU-CHS to a greater extent than native HU (Fig. 4).

For both HU forms, the inactivation diminished with increase of saccharide chain length. The inactivation of HU-CHS by hyaluronan fragments $(\mathrm{pH}$ 5.5, $37{ }^{\circ} \mathrm{C}$ ) was more pronounced on prolonged incubation (Fig. 4b). In $3 \mathrm{~h}$ of incubation, the titer of the surface amino groups decreased by $50 \%$ for $\mathrm{HU}$ and by $34 \%$ for HU-CHS. The results indicated that the $\mathrm{N}$-acetylhexosamines (located at the reducing terminal of hyaluronan fragments, Fig. $3 b$ were more inhibitory toward HU-CHS than toward native HU. In these in vitro experiments, the mixture of hyaluronan fragments simulated the mixture of GLX degradation products in vivo.

The present results demonstrate the ability of $\mathrm{HU}$ and HU-CHS to identify the prevailing fraction of saccharides (neutral or ionized) in the blood flow under various pathological conditions. Different GLX components produce different inhibitory effects on the two HU derivatives, which allow probing the chemical type of GLX degradation products. This approach is helpful in studying the role of neutral saccharides and GLX degradation products in vascular pathology [9], especially in microcirculation disorders [3]. The authors thus tested the pair HU/HU-CHS using a model of microcirculatory damage in the rat hind limb.

\subsection{Model of Rat Microcirculation Injury}

This model of ischemic injury to microcirculation in the rat hind limb has been successfully used earlier in studies on the molecular mechanisms of pain [44] and limb disease [45]. The level of subcutaneous microcirculation was monitored with LDF. In preliminary experiments, the authors tested the hyperemic response and the process of recovery of limb perfusion after ischemia lasting from $5 \mathrm{~min}$ to 5 h. After brief ischemia $(5 \mathrm{~min})$, there was rapid (within $1 \mathrm{~min}$ ) recovery and even an overshoot of the blood flow together with a peak of hyperemia, which then gradually returned to near pre-ischemic 

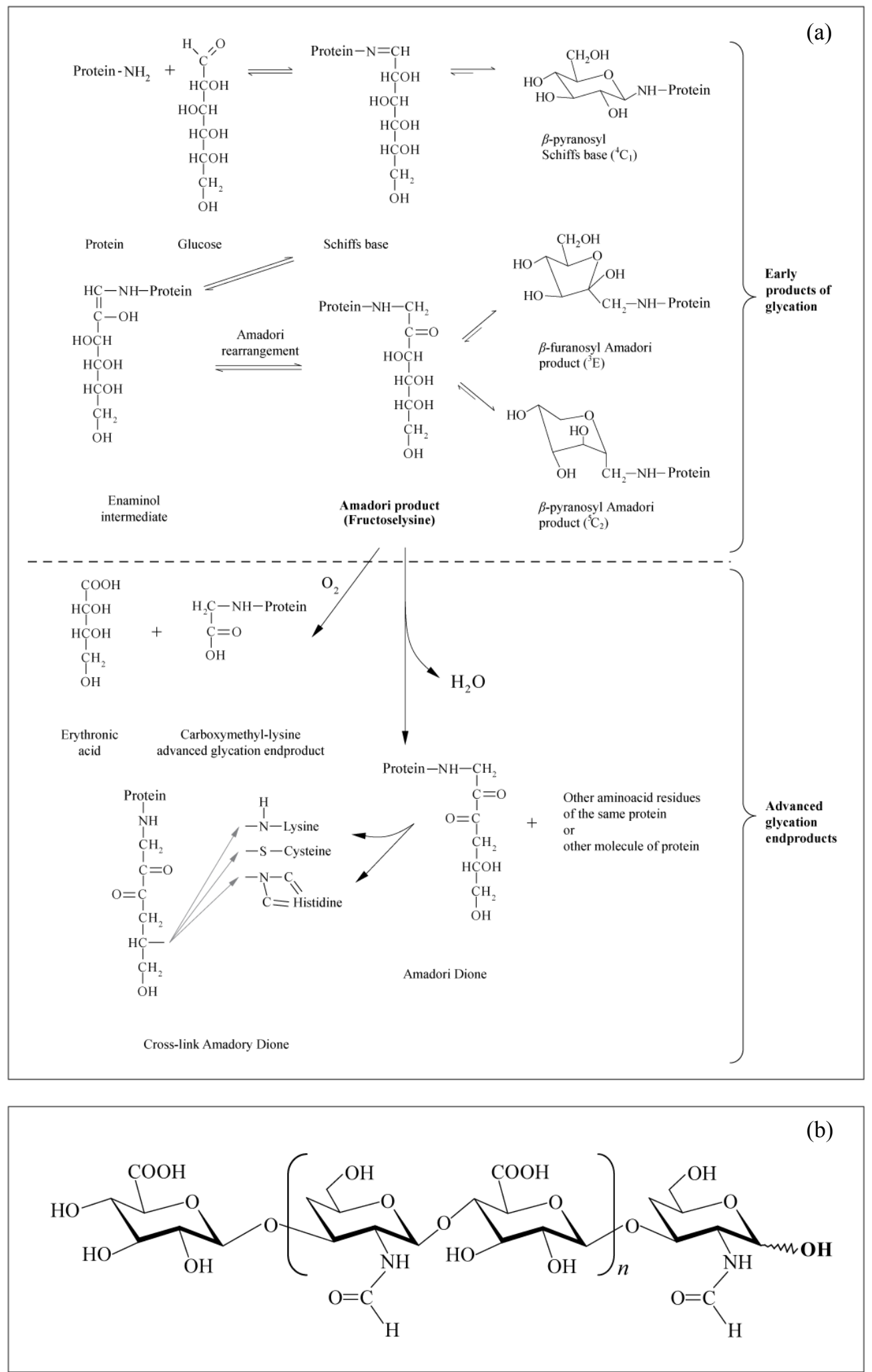

Fig. 3 Protein glycation. The carbonyl group of a reducing saccharide (e.g., glucose) reacts with a protein amino group resulting in early and advanced glycation products (a). The general formula of the hyaluronan degradation product. $\mathrm{N}$-acetylglucosamine at the reducing terminal of this molecule (b). Hyaluronan cleavage unit (with $\beta(1-4)$ linkage) is shown in brackets. 

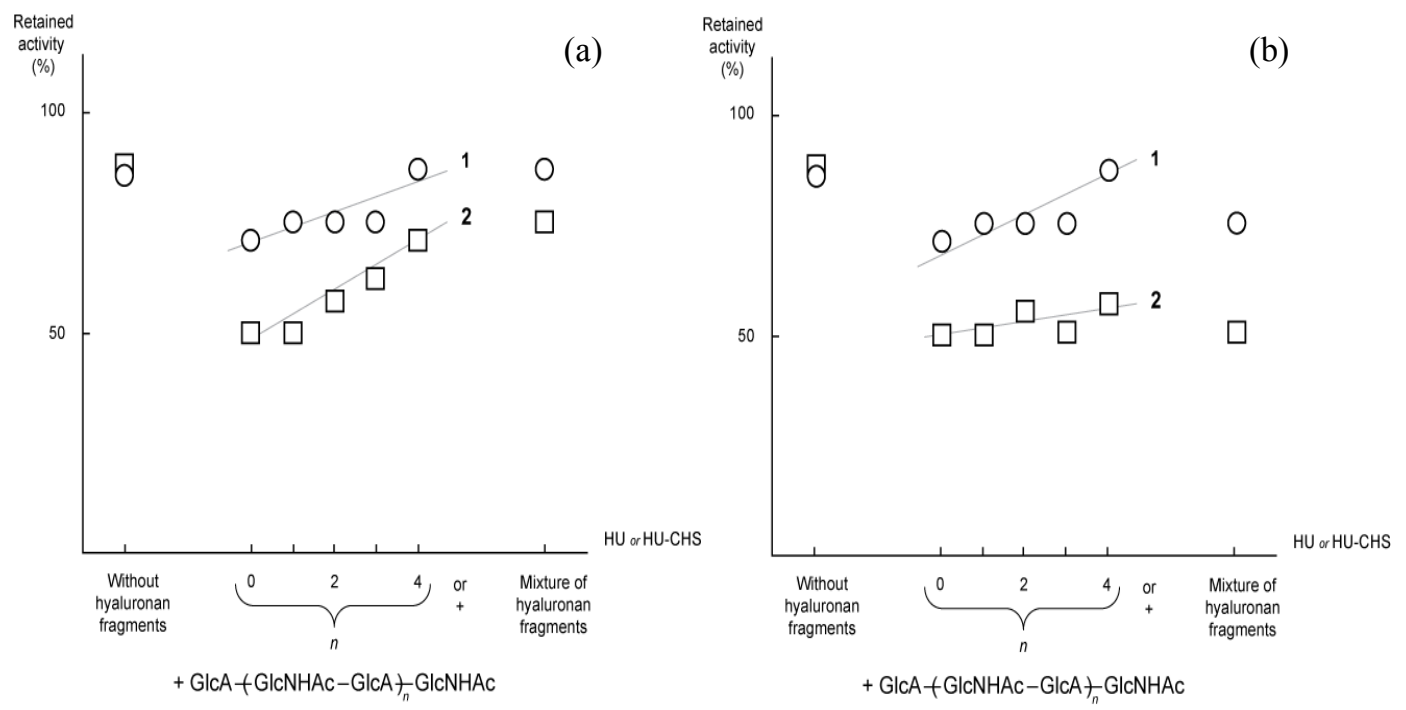

Fig. 4 Residual endoglycosidase activity of (1) HU and (2) HU-CHS in their reactions with hyaluronan fragments with the general formula GlcA-[--GIcNHAc-GlcA-- $]_{n}--$ GIcNHAc, where $n$ varies from 0 to 4, after incubation for (a) $2 \mathrm{~h}$ or (b) $3 \mathrm{~h}$ at $\mathrm{pH} 5.5$ and $37{ }^{\circ} \mathrm{C}$. The reaction mixture was incubated either in the absence or the presence of different hyaluronan fragments $(n=0,1,2,3,4)$ or their mixtures.

levels (Fig. 5). With an ischemic period of $3 \mathrm{~h}$, microcirculation was restored to the pre-ischemic level more slowly (2-3 $\mathrm{min})$; the hyperemic response-long and gradual—developing over $20 \mathrm{~min}$ of the post-ischemic period (Fig. 5). This period of 2-3 min allowed enough time to measure the effects of the tested compounds on blood flow. After brief ischemia (5-60 $\mathrm{min}$ ), however, the microcirculation recovered too fast to measure these effects. On the other hand, $3 \mathrm{~h}$ period of ischemia is shorter than the time needed for the development of significant interstitial edema [44-46]. In the latter scenario, other

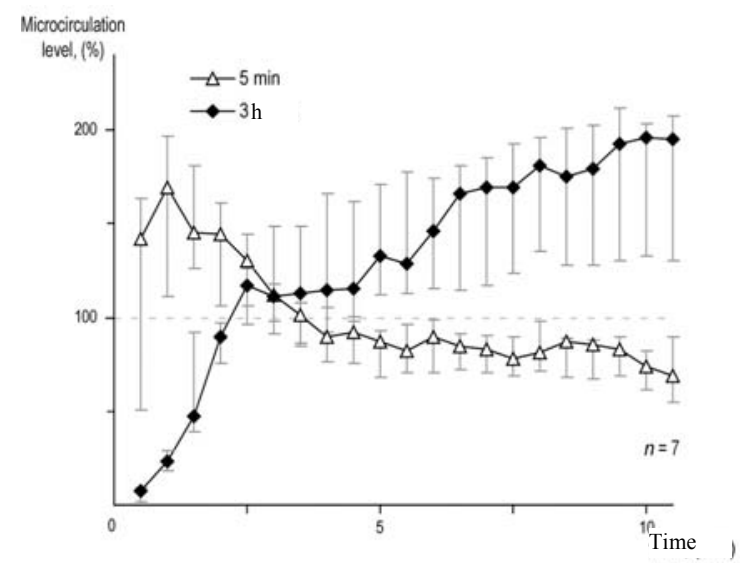

Fig. 5 Levels of microcirculation restoration as measured with LDF in the rat limb after $5 \mathrm{~min}$ and $3 \mathrm{~h}$ of ischemia. factors like reperfusion injury, vasospasm, endothelial swelling, and inflammatory response could lead to irreversible damage to MCB [47].

In these experiments, the authors injected HU/HU-CHS solutions at doses 2.3-3.5 mg protein per kg weight (2,200-3,400 NFU/kg) (Table 1) which was close to the optimal dose interval. In a preliminary test (without ischemia/reperfusion), these agents infused i.v. slightly reduced perfusion, possibly due to hemodilution caused by the injected volume $(1 \mathrm{~mL})$ of the reagent [48]. Early glycation stages evolve promptly (first minutes and hours of reaction; Fig. 3a: early products of glycation). HU activity alteration and titration of its surface amino groups with trinitrobenzolsulfonic acid (for interactions with mono- and disaccharides as well as $\mathrm{N}$ - acetylhexosamines and hyaluronan fragments) warrant this fact [49-51]. Subsequent glycation stages are more continual and can evolve for a few days (Fig. 3a: advanced glycation end products). Handpicked ischemia period of rat limb $(3 \mathrm{~h})$ was measured early glycation stages.

\subsection{Wavelet Analysis of the Scheme 1 Experiments}

The primary data of flowmetry measurements (the 
post-ischemic period, Fig. 6a) were wavelet transformed and presented as an amplitude-frequency spectrum. This spectrum reflected oscillations of microvessels and allowed to analyze the tone-forming mechanisms (Fig. 7).

These mechanisms include the "passive" and "active" factors of MCB. The passive factors are defined as those acting from outside the MCB, such as the pulse wave coming from small arteries and arterioles (pre-MCB) or the "respiratory pump" acting from the venular end (post-MCB). The passive mechanisms (pulse and endothelial waves) induce longitudinal oscillations of blood flow and cyclic changes of blood volume in the MCB [52].

The active factors, precisely conversely, create transverse oscillations of blood flow as a result of direct interactions with the MCB and of cyclic changes in vascular resistance [53, 54]. Since these factors act via the vessel walls and the smooth musculature, they are also called tone-forming [52, 55]. The cyclic changes (vasomotions) can be caused not only by vascular smooth muscles (myogenic rhythm), but also by sympathetic nerves (neurogenic rhythm) or vascular endothelium (endothelial rhythm) $[53,56]$.

In vivo, the passive and active factors function simultaneously and modulate the blood flow to optimize hemodynamics and transcapillary exchange. This complex pattern of vascular regulations was analyzed using LDF flowmetry.

In Scheme 1 experiments, the HU derivatives were injected i.v. before the ischemia, and their effects were followed for a prolonged period. The contribution of the active factors was identified by the specific frequency range; the signal amplitude in a given time interval $(0-300 \mathrm{~s}$ or $300-600 \mathrm{~s})$ was normalized to the pre-ischemic value of this amplitude taken as $100 \%$. The authors found statistically significant differences $(P<0.05)$ between the amplitude values for the neurogenic and myogenic frequency intervals in animals of the control group (Fig. 7). In the subcutaneous blood vessels, the neurogenic interval oscillations reflect sympathetic regulatory mechanisms originated from the internal linings of arterioles and arteriole-venule shunts. Oscillations in the myogenic interval reflect the muscle tone in
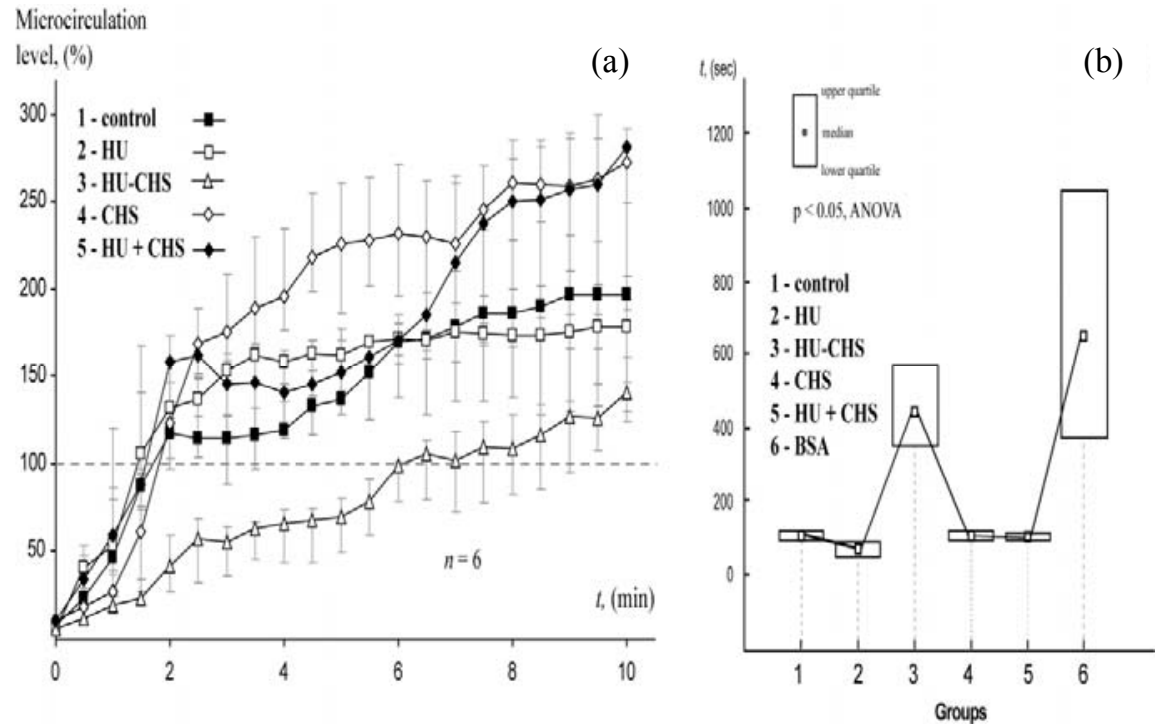

Fig. 6 Post-ischemic levels of microcirculation in the rat limb treated with different agents. Flowmetry measurements made in the Scheme 1 experiments (1 mL bolus $1 \mathrm{~min}$ prior to $3 \mathrm{~h}$ ischemia) are shown. (a) The data represent the median values from the following groups: $1-$ control (saline), $2-\mathrm{HU}, 3-\mathrm{HU}-\mathrm{CHS}, 4-$ free CHS, and 5-mixture of HU and CHS. (b) The time intervals required to reach the initial levels of microcirculation. The data are shown as boxplots within the $25 \%$ and $\mathbf{7 5 \%}$ quartiles (the $\square$ sign denotes the median value). The Scheme 1 data were compared using the Kruskal-Wallis ANOVA test and the median test (statistics shown in the text). 


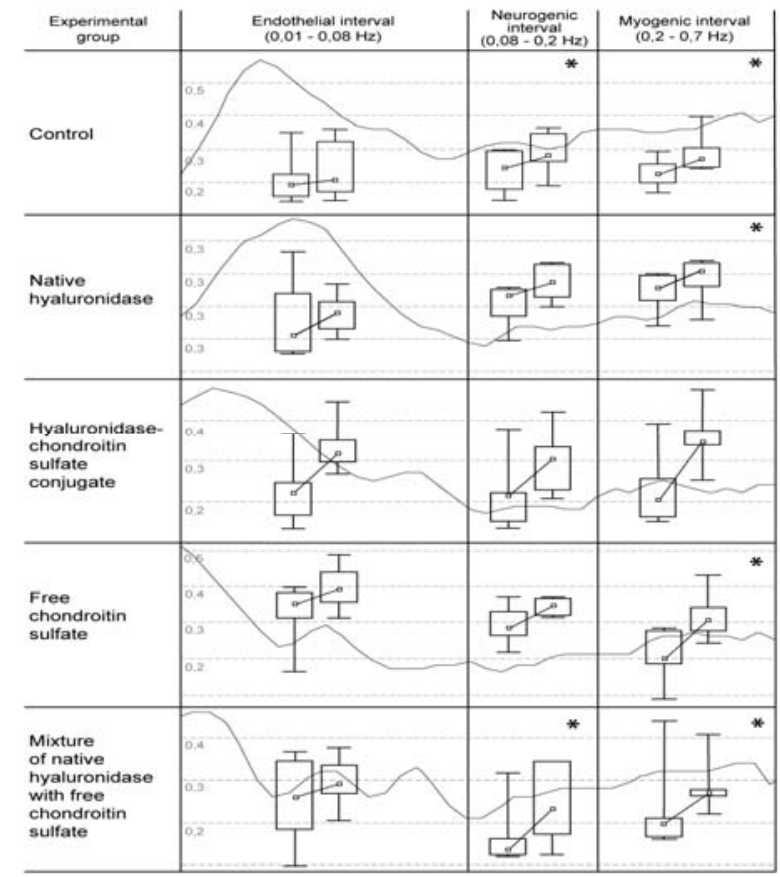

Fig. 7 Wavelet spectra representing the endothelial, neurogenic, and myogenic factors. The data are shown as boxplots within the $25 \%$ and $75 \%$ quartiles (the $\square$ sign denotes the median value; the crosshatches denote the minimal and maximal values). The numbers represent the normalized signal amplitude in the time intervals from $0 \mathrm{~s}$ to $300 \mathrm{~s}$ and from $300 \mathrm{~s}$ to $600 \mathrm{~s}$. *: statistical significance $(P$ $<0.05)$ according to the sign criteria and Wilcoxon test for paired comparisons.

pre-capillaries that bring the blood from the arterioles to the MCB. The significant increase in amplitudes in both neurogenic and myogenic intervals indicates an increase in the blood flow velocity (due to a decrease in vascular resistance) during post-ischemic hyperemia [52]. The authors observed these changes using the mixture of $(\mathrm{HU}+\mathrm{CHS})$, whereas the separate effects of native $\mathrm{HU}$ and free CHS are manifested significantly in the myogenic interval only (Fig. 7). When taken alone, HU-CHS caused no significant effects on the signal amplitude in either frequency interval.

The results suggest that native $\mathrm{HU}$ or free CHS are able to restore the blood flow by acting on pre-capillaries; when injected together their combined action (HU+CHS) involve both pre-capillaries and arterioles. However, covalent binding of CHS to $\mathrm{HU}$ modifies the enzyme so that it inhibits post-ischemic microcirculation (Figs. 6 and 7).

\subsection{Interpretation of Flowmetry Results (Scheme 1)}

The time required for full recovery of microcirculation after ischemia differed in different groups (Fig. 6a). The authors compared the groups using the Kruskal-Wallis ANOVA principle followed by the paired Mann-Whitney test. The analysis showed that the HU group significantly differed from that of HU-CHS, while both groups significantly differed from the other groups. The control group did not differ from the free CHS group and the free CHS+HU group (Fig. 6b). HU significantly accelerated the recovery, whereas HU-CHS slowed it down; the latter was due to the inhibitory effect of GLX degradation products on HU-CHS. The results emphasize the importance of the luminal lining of blood vessels as the source of these products.

It is known that GLX creates resistance to blood flow, forms a molecular barrier to trans-endothelial transport and interacts with blood cells and their movements [3,9]. Ischemia-reperfusion injury and inflammation can destroy GLX in venules and capillaries $[10,12]$. Destruction of hyaluronan can cause capillary dysfunction [3, 32, 33]. The HU derivatives tested in this study were supposed to attack GLX hyaluronan, on the one hand, and react with carbohydrate metabolites present in the circulation, on the other [9]. Under conditions of prolonged ischemia, GLX degradation products can also contribute to the pool of circulating saccharides [3]. The reaction with GLX hyaluronan could be detected by decreased resistance to blood flow, and the reaction with the saccharides by HU inhibition. In the latter, neutral saccharides inactivate the native form of $\mathrm{HU}$, and the ionized GAG (containing $\mathrm{N}$-acetylhexosamines at the reducing terminal) inactivate HU-CHS. According to the wavelet analysis (Fig. 7), HU caused a decrease in microvascular resistance, which supported with the effect of free 
CHS and its mixture with HU. Others have shown that an increase in LDF signal in the myogenic and neurogenic intervals indicates a decrease in vascular resistance [30, 31].

From the LDF data, HU significantly accelerated the recovery of impaired microcirculation after ischemia (Fig. 6). The authors attribute this effect to the endoglycosidase activity of this enzyme, since BSA (which does not possess this enzymatic activity) caused no measurable effects (Fig. 6b).used BSA as the control because it is able (like HU) to pass through damaged endothelial contacts [57].

Exogenous CHS contributes microcirculation recovery (Scheme 1, Fig. 6b). Native HU can really degrade hyaluronan and multiple CHS types [58, 59]. Fragments of hyaluronan and CHS, in particularly, could be composed the pool of glycocalyx degradation products. Presumably, endogenous CHS fragments (in case of native HU action) contribute (like exogenous CHS) fast microcirculation recovery, when HU-CHS has not such effect (Fig. 6a). The comparative experiments demonstrated that there were no differences between $\mathrm{HU}$ and HU-CHS in respect to degradation of CHS. Moreover, microcirculation recovery with mixture of $\mathrm{HU}+\mathrm{CHS}$ was slower than with HU and single CHS only (Fig. 6a). These facts have not warranted mentioned above CHS effect of native $\mathrm{HU}$.

In contrast to native $\mathrm{HU}$, HU-CHS caused the opposite effect, i.e., the slowing of post-ischemic microcirculation recovery (Fig. 6). Apparently the degradation products of GLX that possess $\mathrm{N}$-acetylhexosamines at the reducing terminal inhibited the enzymatic activity of HU-CHS. Moreover, the addition of HU-CHS could introduce additional barriers to the post-ischemic blood flow (Fig. 6). The results suggest that GLX participates in the development of microcirculatory damage, this damage can be repaired by enzymatic treatment. The authors then addressed the question of the importance of the timing of such enzymatic intervention. Authors reasoned that the $\mathrm{HU}$ derivatives would be less effective if injected at the end of the ischemic period. First, the amount of GLX degradation products accumulated during prolonged ischemia might be too high to be removed. Second, the developing hyperemia decreases the dose of active enzyme in injury and the effect of assayed compounds is excluded during the ischemic period. To test these assumptions, the authors conducted experiments according to Scheme 2 (see Methods for details).

\subsection{Wavelet Analysis of the Scheme 2 Experiments}

Fig. 8a shows the primary flowmetry data, and Fig. 9 presents the same data transformed into wavelet spectra. These spectra allowed us to analyze the "active" factors of blood flow that have specific amplitude-frequency "signatures." In general, the results obtained from the Scheme 2 protocols differed from those in Scheme 1. For example, in the control group, the signal amplitude variations in four different intervals (0-300, 300-600, 600-900, and 900-1200 s) differed significantly in the myogenic and endothelial frequency ranges (Fig. 9). This could be explained by a continuous response of the vascular smooth muscle cells to changing intravascular pressure [30] and the metabolic activity of endothelial cells [31]. According to this mechanism, the endothelial cells secrete vasoactive mediators capable of regulating blood flow. As vasoactive mediators act the NO (nitric oxide) [60], a powerful vasodilator of large blood vessels [61, 62], and endothelium-derived hyperpolarizing factor (EDHF), which is able to dilate the arterioles (especially in coronary vessels) and increase microcirculation [62], under conditions of intravascular oxidative stress as well [63].

In these experiments, a bolus of the HU derivatives tested was injected $5 \mathrm{~min}$ prior to the end of the ischemic period (Scheme 2). At that moment, local perfusion was so slight that the injected agents had a very limited distribution volume in the tissue. Accordingly, they had front-loaded contact with 

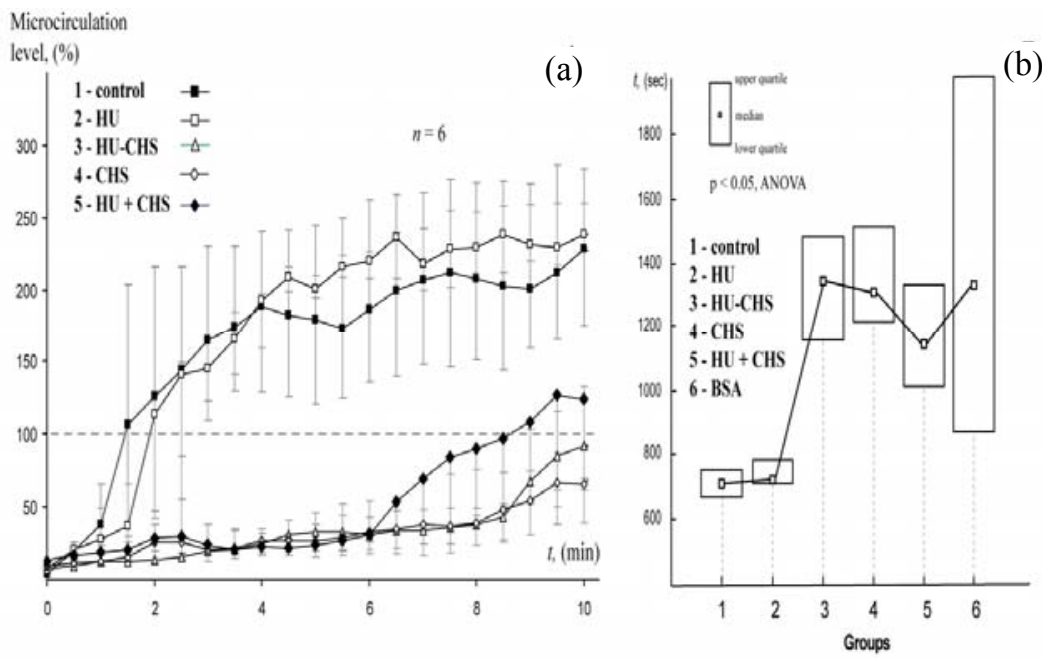

Fig. 8 Post-ischemic levels of microcirculation in the rat limb treated with different agents. Flowmetry measurements made in Scheme 2 experiments ( $1 \mathrm{~mL}$ bolus $5 \mathrm{~min}$ prior to the end of $3 \mathrm{~h}$ ischemia) are shown. (a) The data represent the median values from the following groups: $1-$ control (saline), $2-\mathrm{HU}, 3-\mathrm{HU}-\mathrm{CHS}, 4-$ free CHS, and 5-mixture of HU and CHS; (b) The time intervals required to reach the initial levels of microcirculation. The data are shown as boxplots within the $25 \%$ and $75 \%$ quartiles (the $\square$ sign denotes the median value). The Scheme 2 data were compared using the Kruskal-Wallis ANOVA test and the median test (statistics shown in the text).

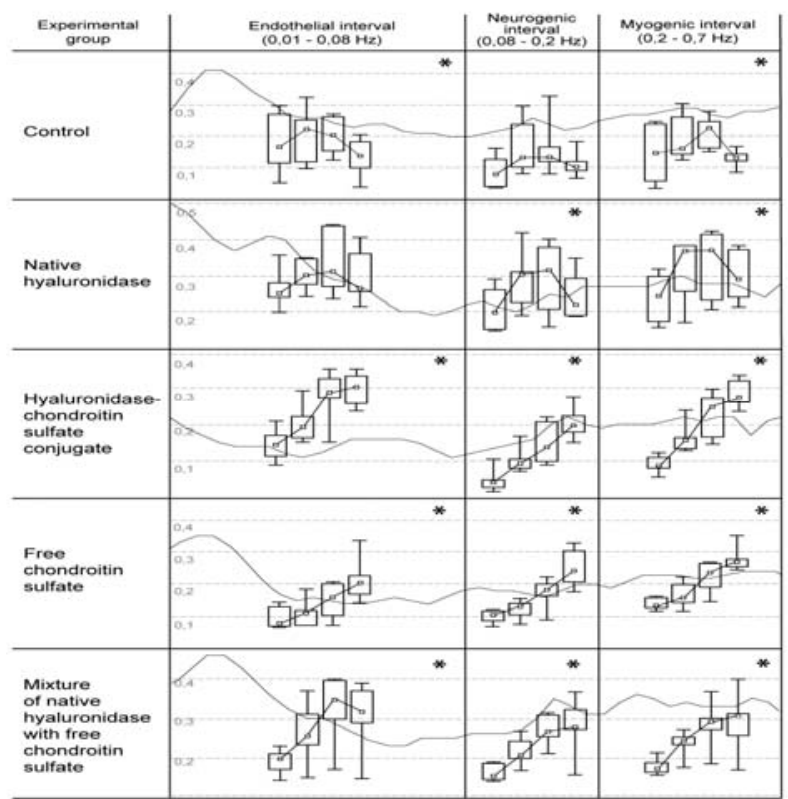

Fig. 9 Wavelet spectra representing the endothelial, neurogenic, and myogenic factors. The data are shown as boxplots within the $25 \%$ and $75 \%$ quartiles (the $\square$ sign denotes the median value; the crosshatches denote the minimal and maximal values). The numbers represent the normalized signal amplitude in the time intervals 0-300, 300-600, 600-900, and 900-1,200 $s$ for experimental groups according to Scheme 2. *: statistical significance $(P<0.05)$ according to the rank analysis of variance (Friedman ANOVA) and computation of the Kendall's coefficient of concordance. metabolites accumulated during ischemia straightway. Under these conditions, the effect of $\mathrm{HU}$ was manifested significantly in the myogenic and neurogenic frequency intervals. The effects of HU-CHS, free CHS, and its mixture with HU were significant for all three frequency intervals (Fig. 9). In the latter case, there was a significant signal increase in the myogenic and neurogenic frequency intervals, which could result from relaxation of the vessel wall and decrease resistance to the blood flow, as well as from activation of endothelial metabolism. As revealed by varying the clamp pressure on the skin, the endothelial factor consistently caused vasodilation and thus counteracted the neurogenic and myogenic increase in vascular resistance (i.e. the decrease of the frequency signal), especially at $>600 \mathrm{~s}$ intervals [30]. Similar effects of blood flow (control) were found during prolonged reperfusion $>900 \mathrm{~s}$ (Fig. 9); those neutralized the counteracting effects of HU-CHS, free CHS, and HU-CHS. The authors propose that (1) if the neurogenic, myogenic and endothelial effects coincide with each other on direction of signal alteration, (2) they develop as compensatory responses to extra load, and that (3) this load is associated with 
the injected HU derivatives.

The binding capacity of GLX toward proteins is well-documented [64]; the same is true for the exogenous GAG (hyaluronan, heparin, heparan sulfate, CHS) [9]. It has been shown that exogenous hyaluronan fragments (deca-saccharides and higher) expelled hyaluronan from the cell surface. In contrast, CHS could not replace hyaluronan, and then accumulated in GLX [3, 65, 66]. In pigs, labeled dextran sulphate (a GAG analog) injected $5 \mathrm{~min}$ before post-ischemic reperfusion accumulated on the surface of the affected myocardial vessel; this process was thought to reduce infarction size [67].

It can be proposed that HU-CHS, free CHS, or its electrostatic complex with native $\mathrm{HU}$ are retained in the GLX net at the time of post-ischemia/reperfusion. This would increase vessel resistance to the renewed blood flow and trigger compensatory myogenic and neurogenic vasodilation (increase of signal). In the endothelial interval, the authors found no significant effect of native HU. Yet, native HU caused significant signal changes (in the neurogenic and myogenic intervals) that can be explained by dilation of pre-capillaries and arterioles. As evidenced by the results in the control group, the vascular tone of pre-capillaries is also influenced by the renewed blood flow (Fig. 9).

\subsection{Flowmetry Data Analysis (Scheme 2)}

Blood flow itself is shown to be a crucial factor in restoring post-ischemic microcirculation (Figure 8a). On the one hand, the results for the control group and the group treated with HU were similar. On the other hand, these two numbers significantly differed from the "flow slowing" effects of HU-CHS, free CHS and HU+CHS (Fig. 8b). The effect of HU was due to its enzymatic activity (inert BSA was not effective) directed toward the GLX structure altered during ischemia. Notably, this enzymatic activity of exogenous HU decreased in the ischemic zone of microcirculation (HU+CHS). In this zone, the mixture
$\mathrm{HU}+\mathrm{CHS}$ may be exposed to an increased level of neutral saccharides. Moreover, the ionized products of GLX degradation (having $\mathrm{N}$-acetylglucosamine at the reducing terminal) inactivate HU-CHS and destroy its electrostatic complexes with CHS, thus implicating GLX in the microcirculatory events. In addition, the proposed retention by GLX of CHS and its complexes inhibits post-ischemic flow recovery (Fig. 8b), probably due to initiation of new hydrodynamic barriers. This suggestion is supported by the results (compare Figs. $6 \mathrm{~b}$ and $8 \mathrm{~b}$ ), which indicate that free $\mathrm{CHS}$ and $\mathrm{HU}+\mathrm{CHS}$ protect microvessels against ischemic injury. In general, the present results underscore the significance of GLX as a potential therapeutic target [7].

\section{Conclusion}

This study presents that pre-ischemic treatment (Scheme 1) by native HU of hyaluronan as part of intravascular GLX improves post-ischemic recovery of microcirculation. The ionized products of GLX degradation (with $\mathrm{N}$-acetylglucosamine at the reducing terminal) accumulating during ischemia are inert toward native $\mathrm{HU}$, but markedly inactivate its modified form, HU-CHS. The inhibitory effect of these products is expressed even more when the tested compounds are injected just before the end of the ischemic period (Scheme 2). Under these conditions, both covalent and electrostatic complexes of HU with CHS are inactivated and free CHS and its mixture with HU lose the anti-ischemic effect. Analysis based on the wavelet spectra suggests that GLX retains HU-CHS, free CHS, and its complexes with native $\mathrm{HU}$, thus slowing the recovery of microcirculation. Since neither BSA nor modified HU-CHS were able to improve post-ischemic recovery, the authors propose that unimpaired HU activity is important for restoring the initial level of microcirculation. The results obtained support the hypothesis that GLX participates in the mechanism of microcirculatory disorder. This provides a 
rationale for new therapeutic approaches to the cases of "optimal" reperfusion absence in patients with cardiovascular disease.

\section{Acknowledgments}

This research was supported by the Federal program "Novel Methodology in Bioengineering" (in the "Enzyme Engineering" and "Biocatalytic Technologies" fields) and by grants RFBR 12-04-00015, 07-04-12057-ofi, and 12-08-00010, as well as by Roszdrav, Rosmedtekhnologia, the Ministry of Health and Social Development and the Ministry of Public Health of the Russian Federation.

The authors extend their gratitude and appreciation to Professor E.I. Chazov, Professor V.N. Smirnov, Professor V.V. Kukharchuk.

\section{References}

[1] D. Bruegger, M. Rehm, M. Jacob, D. Chappell, M. Stoeckelhuber, U. Welsch, et al., Exogenous nitric oxide requires an endothelial glycocalyx to prevent postischemic coronary vascular leak in guinea pig hearts, Crit. Care 12 (2008) 73-84.

[2] M. Rehm, D. Bruegger, F. Christ, P. Conzen, M. Thiel, M. Jacob, et al. Shedding of the endothelial glycocalyx in patients undergoing major vascular surgery with global and regional ischemia, Circulation $116 \quad$ (2007) 1896-1906.

[3] A.V. Maksimenko, A.D. Turashev, No-reflow phenomenon and endothelial glycocalyx of microcirculation, Biochem. Res. International [Online early access]. DOI: 10.1155/2012/859231, http://www.hindawi.com (accessed Jan. 12, 2012).

[4] S. Weinbaum, J.M. Tarbell, E.R. Damiano, The structure and function of the endothelial glycocalyx layer, Annu. Rev. Biomed. Eng. 9 (2007) 121-167.

[5] L.N. Broekhuizen, H.L. Mooij, J.J. Kastelein, E.S. Stroes, H. Vink, M. Nieuwdorp, Endothelial glycocalyx as potential diagnostic and therapeutic target in cardiovascular disease, Curr. Opin. Lipidol. 20 (2009) 57-62.

[6] M. Nieuwdorp, M.C. Meuwese, H. Vink, J.B. Hoekstra, J.J. Kastelein, E.S. Stroes, The endothelial glycocalyx: A potential barrier between health and vascular disease, Curr. Opin. Lipidol. 16 (2005) 507-511.

[7] B.F. Becker, D. Chappell, D. Bruegger, T. Annecke, M. Jacob, Therapeutic strategies targeting the endothelial glycocalyx: Acute deficits, but great potential,
Cardiovasc. Res. 87 (2010) 300-310.

[8] S. Reitsma, D.W. Slaaf, H. Vink, M.A. van Zandvoort, M.G. oude Egbrink, The endothelial glycocalyx: Composition, functions, and visualization, Pflugers Arch. 454 (2007) 345-359.

[9] A.V. Maksimenko, Effects of glycosaminoglycans in vascular events, Chem-Pharm. J. 42 (10) (2008) 3-13. (in Russian with English abstract)

[10] A.W. Mulivor, H.H. Lipowsky, Inflammation- and ischemia-induced shedding of venular glycocalyx, Am. J. Physiol. Heart Circ. Physiol. 286 (2004) 1672-1680.

[11] D. Chappell, M. Jacob, K. Hofmann-Kiefer, M. Rehm, U. Welsch, P. Conzen, et al., Antithrombin reduces shedding of the endothelial glycocalyx following ischemia/reperfusion, Cardiovasc. Res. 83 (2009) 388-396.

[12] S.H. Platts, J. Linden, B.R. Duling, Rapid modification of the glycocalyx caused by ischemia-reperfusion is inhibited by adenosine A2A receptor activation, Am. J. Physiol. Heart Circ. Physiol. 284 (2003) 2360-2367.

[13] A.V. Maksimenko, A.V. Vavaev, Antioxidant enzymes as a potential targets in cardioprotection and treatment of cardiovascular diseases. Enzyme antioxidants: next stage of pharmacological counterwork to the oxidative stress, Heart International 7 (2012) 14-19, DOI: 10.4081/hi.2012.e3, Published Online: Jan. 2, 2012, http://www.pagepress.org/journals/index.php/hi.

[14] A. Maes, F. Van de Werf, J. Nuyts, G. Bormans, W. Desmet, L. Mortelmans, Impaired myocardial tissue perfusion early after successful thrombolysis: Impact on myocardial flow, metabolism, and function at late follow-up, Circulation 92 (1995) 2072-2078.

[15] T. Miura, T. Miki, Limitation of myocardial infarct size in the clinical setting: Current status and challenges in translating animal experiments into clinical therapy, Basic Res. Cardiol. 103 (2008) 501-513.

[16] M.T. Roe, E.M. Ohman, A.C. Maas, R.H. Christenson, K.W. Mahaffey, C.B. Granger, et al., Shifting the open-artery hypothesis downstream: The quest for optimal reperfusion, J. Am. Coll. Cardiol. 37 (2001) 9-18.

[17] A. Abbate, R. Bussani, G. Sinagra, Right ventricular cardiomyocyte apoptosis in patients with acute myocardial infarction of the left ventricular wall, Am. J. Cardiol. 102 (2008) 658-662.

[18] G.J. Wilson, R.J. Diaz, The myocardial no-reflow phenomenon: Role of deltaPKC, Cardiovasc. Res. 73 (2007) 623-625.

[19] R.T. Megens, S. Reitsma, P.H. Schiffers, R.H.P. Hilgers, J.G.R. De May, D.W. Slaaf, et al., Two-photon microscopy of vital murine elastic and muscular arteries: Combined structural and functional imaging with subcellular resolution, J. Vasc. Res. 44 (2007) 87-98.

[20] M. van Zandvoort, W. Engels, K. Douma, L. Beckers, M. 
onde Egbrink, M. Daemen, et al., Two-photon microscopy for imaging of the (atherosclerotic) vascular wall: A proof of concept study, J. Vasc. Res. 41 (2004) $54-63$.

[21] M.I. Noble, A.J. Drake-Holland, H. Vink, Hypothesis: Arterial glycocalyx dysfunction is the first step in the atherothrombotic process, Q. J. M. 101 (2008) 513-518.

[22] B.M. van den Berg, H. Vink, J.A. Spaan, The endothelial glycocalyx protects against myocardial edema, Circ. Res. 92 (2003) 592-594.

[23] L. Galiuto, F. Crea, No-reflow: A heterogeneous clinical phenomenon with multiple therapeutic strategies, Curr. Pharm. Des. 12 (2006) 3807-3815.

[24] A.V. Maksimenko, Y.V. Schechilina, E.G. Tischenko, Role of the glycosaminoglycan microenvironment of hyaluronidase in regulation of its endoglycosidase activity, Biochemistry (Moscow) 68 (8) (2003) 862-868.

[25] A.V. Maksimenko, Y.V. Schechilina, E.G. Tischenko, Resistance of dextran-modified hyaluronidase to inhibition by heparin, Biochemistry (Moscow) 66 (4) (2001) 456-463.

[26] K. Takagaki, K. Kojima, M. Majima, T. Nakamura, I. Kato, M. Endo, Ion-spray spectrometric analysis of glycosaminoglycan oligosaccharides, Glycoconj. J. 9 (1992) 174-179

[27] K.P. Vercruysse, A.R. Lauwers, J.M. Demeester, Kinetic investigation of the action of hyaluronidase on hyaluronan using the Morgan-Elson and neocuproine assays, Biochem. J. 306 (1995) 153-160.

[28] M.M. Bradford, A rapid and sensitive method for the quantitation of microgram quantities of protein utilizing the principle of protein-dye binding, Anal. Biochem. 72 (1976) 248-254.

[29] A.A.C. Sprado, W. Draghetta, S.N. Dellama, H.C.M. Camargo, L.J. Greene, A convenient manual trinitrobenzenesulfonic acid method for monitoring amino acids and peptides in chromatographic column effluents, Anal. Biochem. 96 (1979) 317-321.

[30] A. Humeau, A. Koïtka, P. Abraham, J.L. Saumet, J.P. L'Huillier, Time-frequency analysis of laser Doppler flowmetry signals recorded to a progressive pressure applied locally on anaesthetized healthy rats, Phys. Med. Biol. 49 (2004) 843-857.

[31] Z. Li, E.W. Tam, M.P. Kwan, A.F. Mak, S.C. Lo, M.C. Leung, Effect of prolonged surface pressure on the skin blood flowmotions in anaesthetized rats-An assessment by spectral analysis of laser Doppler flowmetry signals, Phys. Med. Biol. 51 (2006) 2681-2694.

[32] A.P. Stevens, V. Hlady, R.O. Dull, Fluorescence correlation spectroscopy can probe albumin dynamics inside lung endothelial glycocalyx, Am. J. Physiol. Lung Cell Mol. Physiol. 293 (2007) pp. 328-335.
[33] P. Cabrales, B.Y. Vázquez, A.G. Tsai, M. Intaglietta, Microvascular and capillary perfusion following glycocalyx degradation, J. Appl. Physiol. 102 (2007) 2251-2259.

[34] A.J. Furth, Methods for assaying nonenzymatic glycosylation, Anal. Biochem. 175 (1988) 347-360.

[35] A. Goldin, J.A. Beckmam, A.M. Schmidt, M.A. Creager, Advanced glycation end products: Sparking the development of diabetic vascular injury, Circulation 114 (2006) 597-605.

[36] EMBL-EBI [Online], http://www.uniprot.org/uniprot/ Q7YS45.

[37] F. Chen, I. Kakizaki, M. Yamaguchi, K. Kojima, K. Takagaki, M. Endo, Novel products in hyaluronan digested by bovine testicular hyaluronidase, Glycoconj. J. 26 (2009) 559-566.

[38] A. Pollak, H. Coradello, J. Leban, E. Maxa, M. Sternberg, K. Widhalm, et al., Inhibition of alkaline phosphatase activity by glucose, Clin. Chim. Acta. 133 (1983) 15-24.

[39] P.G. Johansen, R.D. Marshall, A. Neuberger, Carbohydrates in protein: The preparation and some of the properties of a glycopeptide from hen egg ovalbumin, Biochem. J. 78 (1961) 518-527.

[40] J. Lechner, F. Wieland, Structure and biosynthesis of prokaryotic glycoproteins, Annu. Rev. Biochem. 58 (1989) 173-194.

[41] R.G. Spiro, Protein glycosylation: nature, distribution, enzymatic formation and disease implications of glycopeptide bonds, Glycobiology 12 (2002) 43-56.

[42] N.T. Seyfried, C.D. Blundell, A.J. Day, A. Almond, Preparation and application of biologically active fluorescent hyaluronan oligosaccharides, Glycobiology 15 (2005) 303-312.

[43] S. Ghatak, S. Misra, B.P. Toole, Hyaluronan oligosaccharides inhibit anchorage-independent growth of tumor cells by suppressing the phosphoinositid 3-kinase/Akt cell survival pathway, J. Biol. Chem. 277 (2002) 38013-38020.

[44] A. Laferriere, M. Millecamps, D.N. Xanthos, W.H. Xiao, C. Siau, M. de Mos, et al., Cutaneous tactile allodynia associated with microvascular dysfunction in muscle, Molecular Pain 4 (2008) 49-59.

[45] F.W. Blaisdell, The pathophysiology of skeletal muscle ischemia and the reperfusion syndrome: A review, Cardiovasc Surgery 10 (6) (2002) 620-630.

[46] B. Bijnens, G.R. Sutherland, Myocardial oedema: A forgotten entity essential to the understanding of regional function after ischaemia or reperfusion injury, Heart 94 (2008) 1117-1119.

[47] R. Jaffe, T. Charron, G. Puley, A. Dick, B.H. Strauss, Microvascular obstruction and the no-reflow phenomenon after percutaneous coronary intervention, 
Circulation 117 (2008) 3152-3156.

[48] A.G. Hudetz, J.D. Wood, B.B. Biswal, I. Krolo, J.P. Kampine, Effect of hemodilution on RBC velocity, supply rate, and hematocrit in the cerebral capillary network, J. Appl. Physiol. 87 (1999) 505-509.

[49] A.D. Turashev, E.G. Tischenko, A.V. Maksimenko, Glycation of native and modified by chondroitin sulfate hyaluronidase with monosacchaarides, Molecular Medicine 3 (2009) 51-56. (in Russian with English abstract)

[50] A.D. Turashev, E.G. Tischenko, A.V. Maksimenko, Nonenzymatic glycosylation of native and modified by chondroitin sulfate hyaluronidase with disaccharides, Molecular Medicine 6 (2009) 50-55. (in Russian with English abstract)

[51] A.D. Turashev, E.G. Tischenko, A.V. Maksimenko, Electrostatic interactions determine glycation of hyaluronidase derivatives with $\mathrm{N}$-acetylhexosamines? Biomedical Chemistry 57 (2011) 624-634. (in Russian with English abstract)

[52] A.I. Krupatkin, V.V. Sidorov, Laser Doppler Flowmetry of Microcirculation, Medicine, Moscow, Russian, 2005.

[53] W. Funk, M. Intaglietta, Spontaneous arteriolar vasomotion, Prog. Appl. Microcirc. 3 (1983) 66-82.

[54] J. Kastrup, J. Bulow, N.A. Lassen, Vasomotion in human skin before and after local heating recorder with laser Doppler flowmetry, Int. J. Microcirc. 8 (1989) 205-215.

[55] A.I. Krupatkin, Dynamic oscillation outline of regulation for capillary hemodynamics, Physiology of Human 33 (2007) 95-103. (in Russian with English abstract)

[56] H.D. Kvernmo, A. Stefanovska, K.A. Kirkeboen, K. Kvernebo, Oscillations in the human cutaneous blood perfusion signal modified by endothelium-dependent and endothelium-independent vasodilators, Microvasc. Res. 57 (1999) 298-309.

[57] J.M. Tarbell, Shear stress and the endothelial transport barrier, Cardiovasc. Res. 87 (2010) 320-330.

[58] L. Gao, H.H. Lipowsky, Composition of the endothelial glycocalyx and its relation to its thickness and diffusion of small solutes, Microvasc. Res. 80 (2010) 394-401.

[59] R. Stern, M. Jedrzejas, Hyaluronidases: genomics, structures, and mechanisms of action, Chem. Rev. 106 (2006) 818-839.

[60] P.M. Vanhoutte, How we learned to say NO, Arterioscler Thromb. Vasc. Biol. 29 (2009) 1156-1160.

[61] D.H. Edwards, Y. Li, T.M. Griffith, Hydrogen peroxide potentiates the EDHF phenomenon by promoting endothelial $\mathrm{Ca}^{2+}$ mobilization, Arterioscler Thromb Vasc. Biol. 28 (2008) 1774-1781.

[62] Y. Liu, D.D. Gutterman, Endothelial cytoskeletal elements are critical for flow-mediated dilation in human coronary arterioles, Med. Biol. Eng. Comput. 46 (2008) 469-478.

[63] W.F. Graier, M. Hecker, Endothelial $\mathrm{H}_{2} \mathrm{O}_{2}$ : A bad guy turning good?, Arterioscler. Thromb. Vasc. Biol. 28 (2008) 1691-1693.

[64] A.V. Maksimenko, Experimental antioxidant biotherapy for protection of the vascular wall by modified forms of superoxide dismutase and catalase, Curr. Pharm. Des. 11 (2005) 2007-2016.

[65] A. Camaioni, V.C. Hascall, M. Yanagishita, A. Salustri, Effects of exogenous hyaluronic acid and serum on matrix organization and stability in the mouse cumulus cell-oocyte complex, J. Biol. Chem. 268 (1993) 20473-20481.

[66] T.N. Wight, M.J. Merrilees, Proteoglycan in atherosclerosis and restenosis: Key roles for versican, Circ. Res. 94 (2004) 1158-1167.

[67] Y. Banz, O.M. Hess, S.C. Robson, D. Mettler, P. Meier, A. Haeberli, et al., Locally targeted cytoprotection with dextran sulfate attenuates experimental porcine myocardial ischaemia/reperfusion injury, Eur. Heart J. 26 (2005) 2334-2343. 